\title{
Effects of transport time and feeding type on weight loss, meat quality and behavior of broilers
}

\author{
Yajie Fu ${ }^{1, a}$, Jingwen Yin ${ }^{1, a}$, Ning Zhao ${ }^{1}$, Ge Xue ${ }^{1}$, Runxiang Zhang ${ }^{2}$, Jianhong $\mathrm{Li}^{1{ }^{1,}}$, and Jun $\mathrm{Bao}^{2, *}$
}

\author{
* Corresponding Authors: \\ Jianhong Li \\ Tel: +86-0451-55190321 \\ E-mail: jhli@neau.edu.cn \\ Jun Bao \\ E-mail: junbaoneau@sina.com \\ ${ }^{1}$ College of Life Science, Northeast \\ Agricultural University, Harbin, Heilongjiang \\ 150030, China \\ ${ }^{2}$ College of Animal Science and Technology, \\ Northeast Agricultural University, Harbin, \\ Heilongjiang 150030, China \\ a These authors contributed equally to this \\ work \\ ORCID \\ Yajie Fu \\ https://orcid.org/0000-0003-4554-3095 \\ Jingwen Yin \\ https://orcid.org/0000-0003-1739-8935 \\ Ning Zhao \\ https://orcid.org/0000-0001-9179-5459 \\ Ge Xue \\ https://orcid.org/0000-0002-5023-4011 \\ Runxiang Zhang \\ https://orcid.org/0000-0002-6315-9399 \\ Jianhong Li \\ https://orcid.org/0000-0002-7736-0333 \\ Jun Bao \\ https://orcid.org/0000-0003-4698-7018
}

Submitted Aug 26, 2021; Revised Nov 10, 2021; Accepted Jan 12, 2022
Objective: The purpose of this study is to determine the optimal time of transportation of floor-feed and scatter-feed broilers.

Methods: Eighty healthy Arbor Acres (AA) broilers (21-day-old, 624.4 g, male, standard error $=6.65$ ) were selected and randomly divided into two experimental groups (floor-feed and scatter-feed), then fed for three weeks. The experiment comprised a $2 \times 4$ factorial design with 2 feed patterns (floor-feed and scatter-feed) and 4 transport periods (2, 3, 4, and $5 \mathrm{~h}$ ), and 4 replicates of 5 broilers (54-day-old, $2243 \mathrm{~g}$, standard error $=46.65$ ) was used to compare weight loss, meat quality and behavior index of different groups.

Results: It appeared that drip loss, meat color and resting behavior of experimental broilers changed as length of transportation $(\mathrm{p}<0.05)$, however, weight loss and $\mathrm{pH}$ were not significantly transformed $(\mathrm{p}>0.05)$. Compared with floor-feed group, broilers in scatter-feed group had lower $\mathrm{pH}$ at 24 hours $(3 \mathrm{~h})$ and different behavioral indicators $(\mathrm{p}<0.05)$. Especially indicators after $3 \mathrm{~h}$ transportation, there were obvious differences between the two feeding modes in the behavior reaction of stress events before slaughter with different transport duration $(p<0.05)$. The fluctuation of data on resting behavior with scatter-feed was significantly higher than that of floor-feed broilers. There was no interaction between transport time and different feeding methods for index tested of our experiment ( $p>0.05)$.

Conclusion: Comprehensive analysis showed that the maximum transport duration of floor-feed and scatter-feed broilers should not exceed $3 \mathrm{~h}$, and scatter-feed broilers were more likely prone to fear.

Keywords: Arbor Acres Broiler; Feeding Methods; Meat Quality; Stress Behavior; Transport Time; Weight Loss

\section{INTRODUCTION}

Consumers prefer scientifically raised broiler meats rather than other meats because of their low-price and easy-to-cook properties. Whereas, to expand poultry production blindly would produce more frequent transport impairments such as welfare reduction, weight loss, and meat metamorphism [1-3]. Therefore, to pursue efficient economic returns, transport stress must be reduced in the scientific and rapid production of broilers.

Many techniques to decrease the transport stress of birds have been used, such as feed addition [4,5], improving transportation and vehicle facilities [6,7], microclimate temperature control [8], etc. Compared to these methods, controlling transport distance is the most economical way to decrease transport stress. Considering with the increased scale of industrial intensive poultry farming, reasonable thresholds for transport distance should be determined to ensure the meat quality and welfare of commercial broilers before slaughter.

As an important premortem stressor, the influence of transport stress does not stop at 
slaughter, but also continues to affect conversion of muscle to meat $[9,10]$. Different transport times could alter stress levels by changing oxidation levels, heat production, and $\mathrm{pH}$, which then manifest as altering cytochrome content, protein content and configuration, and internal and external water distribution $[10,11]$. The damaged appearance of raw meat with too dark or too light color and low water-holding ability may reduce purchasing desire and eating experience of consumers $[12,13]$. Because of higher antioxidant levels with higher muscle fiber strength, mitochondrial function, nutrient content and lower glycogen content, meat quality of free-range broilers seems fresher than plain broilers [14]. Floor-feed is generally adopted in commercial poultry farming. Studies have found that mortality and weightlessness of broilers increase with the extension of transportation time $[1,2]$. The results of floor-feed broilers in the experimental base were not the same. Owens and Sams [9] found that the $\mathrm{pH}$ of pectoral muscle increased significantly and $\mathrm{L}^{\star}$ decreased significantly after transportation for $3 \mathrm{~h}$. Gou et al [3] found that antioxidant capacity and body weight of broilers decreased, but there was no significant difference in meat quality including $\mathrm{pH}$ and meat color. Pan et al [6] found in the study that the $\mathrm{pH}$ of floor-feed broilers under experimental conditions after $3 \mathrm{~h}$ transportation did not change significantly, $\mathrm{a}^{*}$ significantly decreased, $\mathrm{b}^{*}$ significantly increased, and the deterioration of meat quality was significantly decreased after the addition of antioxidant. Free-range farming can change meat quality and body performance of poultry [14]. It was found that plasma corticosterone content of two organic scatter-feed hens decreased rapidly during the first 6 hours of transportation [15]. However, there is still a lack of clear comparison results about the effects on floor-feed and scatter-feed broilers after transportation time.

As recognized by the World Organization for Animal Health (OIE) good animal welfare during transport is one of the most important pre-harvest variables with respect to meat quality and should be considered a critical control point [16, 17]. Behavioral changes reflect emotional changes caused by transport stress. Cashmana et al [18] found that the degree of stress fluctuated with prolonged transport stress before slaughter. Due to differences in broiler breeds and growing environments, there are differences in the psychological and physiological sensitivities of organisms to transport pressure [19]. We hypothesize that some effect would be caused by transport time on broilers. After a certain period of transportation, the damage of stress exceeds the homeostatic adjustment and recovery ability of broilers, leading to significant increase in weight loss and deterioration of meat quality. At the same time, the degree of fear in broilers may be difficult to alleviate and will produce obvious changes in behavior indicators. However, there may be differences between broilers reared in floor-feed and scatter-feed.
The objective of the present study was to determine the appropriate transportation time for floor-feed and scatter-feed broilers by testing the effects of the different transportation time on weight loss, meat quality and behavior in broilers.

\section{MATERIALS AND METHODS}

\section{Experimental animals and design}

All experimental protocols and procedures were approved by Northeast Agricultural University Animal Care and Use Committee (IACUCNEAU20150616).

Arbor Acres broilers (AA) ( $\mathrm{n}=100$, male, 1-day-old) with $39.59 \mathrm{~g}$ of average initial body weight $($ standard error $=2.09$ ) were selected as test animals. During the first 21 days, the floor of AA broilers was padded with $10 \mathrm{~cm}$ thick sawdust, with a feeding density of 8 to $10 \mathrm{birds} / \mathrm{m}^{2}$. Natural ventilation with $60 \%$ to $70 \%$ of relative humidity was used in the chicken house. The temperature inside $\left(34^{\circ} \mathrm{C}\right.$ to $35^{\circ} \mathrm{C}$ in the first 7 days, reduced by $2^{\circ} \mathrm{C}$ to $3^{\circ} \mathrm{C}$ every 7 days until $18^{\circ} \mathrm{C}$ to $20^{\circ} \mathrm{C}$ ) and ordinary incandescent lighting $(23 \mathrm{~h}$ in the first 3 days; then $12 \mathrm{~h}$ every day, from 7:00 am to 7:00 pm) were strictly controlled. Three-week-old broilers $(\mathrm{n}=80)$ with $624.4 \mathrm{~g}$ (standard error $=6.65$ ) were randomly selected and divided into two groups, including floor-feed and scatter-feed groups. The floor-feed group $(n=40)$ was raised on the indoor floor (relative humidity, $48 \%$ to $50 \%$; stable temperature, $18^{\circ} \mathrm{C}$ to $20^{\circ} \mathrm{C}$; feeding density, 8 birds $/ \mathrm{m} 2$, natural light). Scatter-feed group $(n=40)$ was raised in a plastic greenhouse with a metal frame covered by the plastic film ( $4 \mathrm{~m}$ length, $2 \mathrm{~m}$ width, 1.2 $\mathrm{m}$ height, $5 \mathrm{~cm}$ thick padding replaced every 4 days; relative humidity, $30 \%$ to $40 \%$; stable temperature, $22^{\circ} \mathrm{C}$ to $26^{\circ} \mathrm{C}$; feeding density, 5 birds $/ \mathrm{m}^{2}$ ) as a sports field (activities and rest with sun-shade net) during day-time (from 7.00 am to $5.00 \mathrm{pm}$ ), and was forced into chicken house during nighttime. Experimental broilers were given free access to feed and water. Broilers were fed with an early-stage diet (metabolizable energy of $12.1 \mathrm{MJ} / \mathrm{kg}$ and crude protein of $21.0 \%$ for 1 to 21 days of age) and a late-stage diet (metabolizable energy of $12.6 \mathrm{MJ} / \mathrm{kg}$ and crude protein of $19.0 \%$ for 22 to 43 days of age).

The forty 54 -day-old healthy broilers $(2,243 \pm 46.65 \mathrm{~g})$ from each of the above two feeding methods were weighted and randomly divided into four groups (4 replicates and 5 chickens each). After $10 \mathrm{~h}$ of limited feeding treatment, all chickens were caged and transported (5 per carton). Each group of broilers was transported between the country roads for $2,3,4$, and $5 \mathrm{~h}$, on the day of transportation, the weather was overcast, and the average temperature was $20^{\circ} \mathrm{C}$. The broilers from each treatment group were immediately weighted, then rested for 1 hour, hung for 12 seconds, and killed by decapitation. During the resting and hanging period, a video camera, GoPro2 HD (GoPro Inc., San Mateo, 
CA, USA) was used to record the behavior of chickens. The pectoral muscle of broiler chickens was taken and examined.

\section{Sample collection and index determination Weight loss:}

$$
\begin{aligned}
& \text { Weight loss }(\mathrm{Ws}) \\
& \text { = body weight before fasting }\left(\mathrm{W}_{1}\right) \\
& \quad \text { - body weight before slaughter }\left(\mathrm{W}_{2}\right)
\end{aligned}
$$

\section{Meat quality:}

i) $\mathrm{pH} 1$ and $\mathrm{pH}_{2}$ : Acidimeter was calibrated before the sample determination using a standard solution of $\mathrm{pH}$ (4.003, 6.864, and 9.182). $\mathrm{pH}_{1}$ and $\mathrm{pH}_{2}$ of breast muscles were determined by a $\mathrm{pH}$ meter within 45 to $60 \mathrm{~min}$ and 24 hours, respectively (Elta-320; Mettler Toled, Shanghai, China). The probe was inserted directly into muscle tissue, and the reading was acquired after stabilizing it. The breast muscles were wrapped with plastic wraps and stored at $4^{\circ} \mathrm{C}$ after determining $\mathrm{pH}$.

ii) Meat color: The breast muscle was cut, and the thickness of the muscle was $1.5 \mathrm{~cm}$. The meat color $\left(\mathrm{L}^{*}, \mathrm{a}^{*}\right.$, and $\mathrm{b}^{*}$ values) was determined using a Chroma meter (CR-400; Konica Minolta, Tokyo, Japan) at $1 \mathrm{~h}$ after the slaughter in three regions of the left pectoral muscle. Finally, the average value was obtained.

iii) Determination of drip loss: After slaughter, breast muscles were trimmed into meat cuts $(5 \mathrm{~cm} \times 3 \mathrm{~cm} \times 3 \mathrm{~cm})$, and the weight of breast muscles $\left(\mathrm{W}_{1}\right)$ was measured. Then, the meat cuts were tied with thin wires and transferred to a $50 \mathrm{~mL}$ cold storage tube at $4^{\circ} \mathrm{C}$ for $24 \mathrm{~h}$. After absorbing surface moisture using a clean filter paper, meat cuts were reweighed $\left(\mathrm{W}_{2}\right)$. Drip loss percentage was calculated according to the formula: Drip loss $(\%)=\left(\mathrm{W}_{1}-\mathrm{W}_{2}\right) / \mathrm{W}_{1} \times 100 \%$.

iv) Shear force: After determining drip loss, meat samples were placed in food bags and then placed in a water bath pot at $80^{\circ} \mathrm{C}$ until the center temperature of meat reached $75^{\circ} \mathrm{C}$ and maintained at $75^{\circ} \mathrm{C}$ for $10 \mathrm{~min}$. Then, meat samples were cut into $2.5 \mathrm{~cm}$ and $1.0 \mathrm{~cm}$ diameters using scissors and sheared using a tenderometer (C-LM3; College of Engineering, Northeast Agricultural University, Harbin, China) for the maximum shear force. The Warner-Bratzler single blade sheared the meat column in the direction perpendicular to the muscle fiber, with the shear velocity of $5 \mathrm{~mm} / \mathrm{s}$. Each meat sample was cut 3 times, and the average value was obtained.

\section{Behavior:}

GoPro2 HD (GoPro Inc., USA) (resolutions: 1,080 p: 1,920, 1,080 , and 30 FPS) was used to avoid interference by direct contact with the animals. The cameras were placed around the broiler lounge and the slaughter room in the same arrangement.

i) Behavior during rest: After the end of the transport, the videos were recorded after the broiler entered the lounge to adapt to the environment for $30 \mathrm{~min}$. The recording time was $30 \mathrm{~min}$. During the behavior observation period, it was sampled instantly every $30 \mathrm{~s}$. The behavior data of broilers were expressed by the number of activities occurring during observation time. Behavior definitions are shown in Table 1.

ii) Struggling behavior before slaughter: The total duration of wing flapping was recorded from hanging to slaughter. Vocalisations from the beginning of poultry hanging observation were scored according to the corresponding four levels: a) poultry does not sound, score 0 ; b) poultry makes a simple weak sound, score $1 ; c)$ poultry makes a weak sound for a long time, score 2 ; d) poultry makes a bright sound for a long time, score 3 .

\section{Statistical analysis}

The test data of weight loss, meat quality and behavioral indicators were tested by the Univariate process in the SAS9.1 before the analysis. The quantitative data, which did not conform to the normal distribution, were converted by log, sine and inverse string, square root, etc. One-way analysis of variance (ANOVA) analysis was done, and the multiple

\begin{tabular}{|c|c|}
\hline Items & Definition \\
\hline \multicolumn{2}{|l|}{ Behavioral variables } \\
\hline Head movement & The head of the poultry rotates rapidly, indicating that it is visually alert to the surroundings \\
\hline Preening & The beak is used to comb through or manipulate any area of feathers on the bird's own body \\
\hline Meaningless pecking behavior & Non-offensive peck on other things, including a cage, a feather, an empty peck \\
\hline Foraging & Peck the floor while planing or head moving below the tail \\
\hline \multicolumn{2}{|l|}{ State behavior } \\
\hline Walking & At least one step or more \\
\hline Standing & Legs landing without showing other state behavior in the definition \\
\hline Lying & Bird is in the sitting position, motionless with its body contacting the floor of the crate \\
\hline
\end{tabular}
comparisons were carried out by the Duncan test method.

Table 1. Behavioural categories and their definitions

Debut et al [31]. 
Experiment II: $\mathrm{y}_{\mathrm{ij}}=\mu \mathrm{E}_{\mathrm{i}} \mathrm{W}_{\mathrm{j}}(\mathrm{WE})_{\mathrm{ij}} \mathrm{e}_{\mathrm{ij}}$

$\mu$, total mean effect; $\mathrm{E}$, feeding methods; $\mathrm{W}$, transport time; e, random error.

\section{RESULTS}

\section{Weight loss}

As shown in Table 2, transport time had no significant effect on weight loss both in the floor-feed and scatter-feed broilers $(\mathrm{p}>0.05)$.

\section{Meat quality}

Table 3 shows that the impact of the transport phase on floor-feed and scatter-feed broilers' meat quality is multifaceted. Disparate transport time had no effect on $\mathrm{pH}_{1}$ and $\mathrm{pH}_{2}$ ( $p>0.05)$, but resulted in significantly increased drip loss, flesh-color $\mathrm{L}^{*}$ both in floor-feed and scatter-feed groups $(\mathrm{p}<$

Table 2. Effect of the length of transport and the feed pattern on the fresh weight of broilers at 54-days

\begin{tabular}{|c|c|c|c|c|c|c|c|c|c|c|}
\hline \multirow[b]{2}{*}{ Items } & \multirow{2}{*}{$\begin{array}{c}\text { Feeding } \\
\text { pattern }\end{array}$} & \multicolumn{5}{|c|}{ Length of transport $(\mathrm{h})^{1)}$} & \multirow[b]{2}{*}{$\mathbf{P}_{\mathrm{L}}$} & \multicolumn{3}{|c|}{ Effect $^{2)}$} \\
\hline & & 0 & 2 & 3 & 4 & 5 & & Pattern & Length & $\begin{array}{l}\text { Pattern } \\
\text { xlength }\end{array}$ \\
\hline \multirow[t]{3}{*}{ Weight (g) } & Floor-feed & $2,249.58 \pm 42.15$ & $2,140.21 \pm 150.23$ & $2,155.07 \pm 32.14$ & $2,113.95 \pm 45.45$ & $2,116.67 \pm 41.89$ & NS & NS & NS & NS \\
\hline & Scatter-feed & $2,231.43 \pm 35.67$ & $2,143.17 \pm 26.35$ & $2,109.16 \pm 37.41$ & $2,156.32 \pm 32.63$ & $2,026.51 \pm 97.43$ & NS & & & \\
\hline & $P_{F}$ & NS & NS & NS & NS & NS & & & & \\
\hline \multirow[t]{3}{*}{ Weight loss (g) } & Floor-feed & - & $104.00 \pm 108.51$ & $93.00 \pm 20.22$ & $122.22 \pm 34.84$ & $124.00 \pm 29.72$ & NS & NS & NS & NS \\
\hline & Scatter-feed & - & $80.00 \pm 6.61$ & $112.00 \pm 14.02$ & $95.00 \pm 11.93$ & $235.00 \pm 109.82$ & NS & & & \\
\hline & $P_{F}$ & - & NS & NS & NS & NS & & & & \\
\hline
\end{tabular}

$P_{L}$, the effect of transportation time on fresh weight; $P_{F}$, the effect of feeding pattern on fresh weight.

1) Results of one-factor analysis of variance.

2) Results of two-factor analysis of variance.

NS, no significant difference $(p>0.05)$.

Table 3. Effect of the length of transport and the feed pattern on breast meat quality of broilers at 54-days

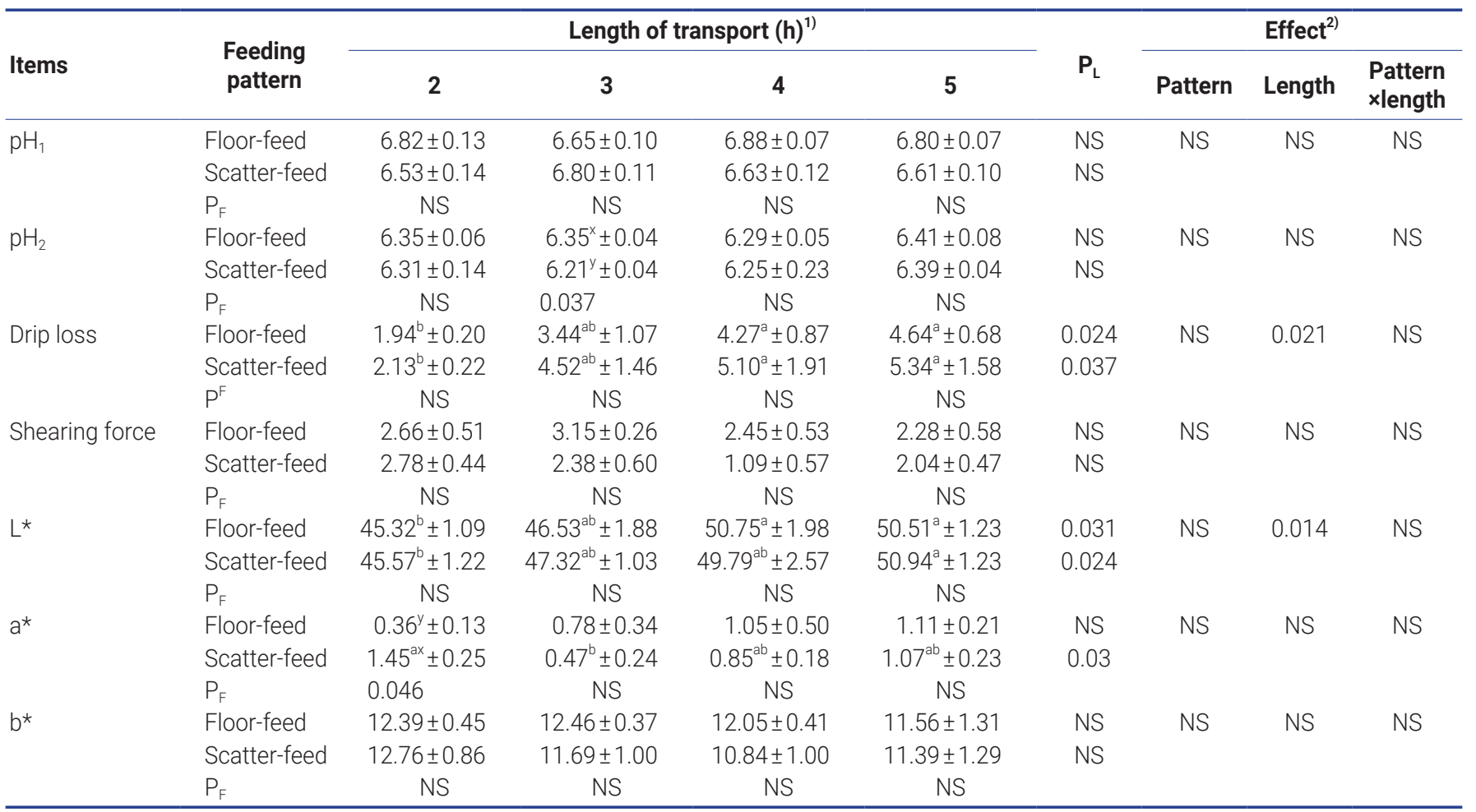

$\mathrm{P}_{\mathrm{L}}$, the effect of transportation time on breast meat quality; $\mathrm{P}_{\mathrm{F}}$, the effect of feeding pattern on breast meat quality.

1) Results of one-factor analysis of variance.

${ }^{2)}$ Results of two-factor analysis of variance.

$N S$, no significant difference $(p>0.05)$.

$a, b$ Significant difference in a row $(p<0.05)$.

${ }^{x, y}$ Significant difference in a column $(p<0.05)$. 
$0.05)$, while reduced $\mathrm{a}^{*}$ value only with scatter-feed $(\mathrm{p}<0.05)$. The meat quality comparison on transportation revealed a higher $\mathrm{pH}_{2}(3 \mathrm{~h})$ in floor-feed than that in scatter-feed group $(\mathrm{p}<0.05)$. There was no significant interaction between feeding mode and fasting length of all broiler indicators for the data of meat quality in our experiment ( $p>0.05)$.

\section{Behavior of broilers during rest}

As shown in Table 4, the changes in behavior at rest differed according to time spent in transport, with remarkable reduction in up-regulation energy-consuming behavior (walking in 4, $5 \mathrm{~h}$; standing in 3, 4, $5 \mathrm{~h} ; \mathrm{p}<0.05$ ), conversely substantial increase in reduced energy-consuming behavior (lying in 3 , $4,5 \mathrm{~h} ; \mathrm{p}<0.05)$ in scatter-feed broilers. Fluctuation in other natural behavior also was associated with transport duration with scatter-feed: lower preening in $4 \mathrm{~h}(\mathrm{p}<0.05)$; less head moving in $5 \mathrm{~h}(\mathrm{p}<0.05)$; diminished meaningless pecking in $3 \mathrm{~h}$ and $5 \mathrm{~h}(\mathrm{p}<0.05)$; nevertheless, no remarkably changed foraging ( $p>0.05)$. All behavior of floor-feed broilers during rest was shown with no significant alteration except for lying which was higher after 3,4 , and $5 \mathrm{~h}$ transport than in $2 \mathrm{~h}$ group $(\mathrm{p}<0.05)$.

When the behavior indicators of each group were collected, all the behavior during rest was different between the feeding methods $(\mathrm{p}<0.05)$. And most of the data showed the two feed patterns significantly differed after $3 \mathrm{~h}$ transport $(\mathrm{p}<0.05)$ in Table 4 , while at $4 \mathrm{~h}$, there was no obvious change in all behavioral indicators ( $p>0.05)$. Standing, walking, and preening, foraging behavior of floor-feed broilers were significantly lower than that with scatter-feed at $3 \mathrm{~h}$, while lying and head movement behavior were significantly higher $(\mathrm{p}<0.05)$.

\section{Struggling behavior before slaughter}

As shown in Table 5, transportation time and feeding mode have no significant influence on the pre-mortem struggle behavior of broilers $(\mathrm{p}>0.05)$.

\section{DISCUSSION}

\section{Effects of different transport times on weight loss of broilers}

Transport stress results in serious weight loss, increasing injury rates, reducing production performance, and causing mass deaths in severe cases [1-3]. Weight loss occurred due to energy consumption and excretion, during poultry transportation. Compared with some studies that showed a huge difference in weightlessness $[3,20]$, there was no prominent

Table 4. Effect of the length of transport and the feed pattern on behavior during rest of broilers at 54-days

\begin{tabular}{|c|c|c|c|c|c|c|c|c|c|}
\hline \multirow[b]{2}{*}{ Items } & \multirow{2}{*}{$\begin{array}{c}\text { Feeding } \\
\text { pattern }\end{array}$} & \multicolumn{4}{|c|}{ Length of transport $(h)^{1)}$} & \multirow[b]{2}{*}{$\mathbf{P}_{\mathrm{L}}$} & \multicolumn{3}{|c|}{ Effect $^{2)}$} \\
\hline & & 2 & 3 & 4 & 5 & & Pattern & Length & $\begin{array}{l}\text { Pattern } \\
\text { xlength }\end{array}$ \\
\hline \multirow[t]{3}{*}{ Standing } & Floor-feed & $12.33^{y} \pm 3.06$ & $6.33^{y} \pm 1.62$ & $6.67 \pm 3.80$ & $4.00^{y} \pm 1.13$ & 0.037 & 0.016 & 0.009 & NS \\
\hline & Scatter-feed & $51.67^{\mathrm{ax}} \pm 5.75$ & $22.67^{b x} \pm 2.34$ & $17.33^{b} \pm 5.42$ & $26.67^{b x} \pm 3.21$ & 0.029 & & & \\
\hline & $P_{F}$ & 0.020 & 0.016 & NS & 0.024 & & & & \\
\hline \multirow[t]{3}{*}{ Walking } & Floor-feed & $2.00 \pm 0.82$ & $1.33^{y} \pm 0.62$ & $0.67 \pm 0.41$ & $0.67 \pm 0.67$ & NS & 0.033 & 0.027 & NS \\
\hline & Scatter-feed & $3.63^{\mathrm{ab}} \pm 1.70$ & $7.67^{\mathrm{ax}} \pm 2.01$ & $1.67^{\mathrm{b}} \pm 1.67$ & $2.33^{b} \pm 0.67$ & 0.023 & & & \\
\hline & $P_{F}$ & NS & 0.024 & NS & NS & & & & \\
\hline \multirow[t]{3}{*}{ Lying } & Floor-feed & $85.67^{b x} \pm 3.36$ & $92.33^{\mathrm{abx}} \pm 2.07$ & $92.67^{\mathrm{ab}} \pm 4.10$ & $95.33^{\mathrm{ax}} \pm 1.22$ & 0.044 & 0.015 & 0.007 & NS \\
\hline & Scatter-feed & $44.67^{\text {by }} \pm 6.78$ & $69.67^{\text {ay }} \pm 3.05$ & $81.00^{\mathrm{a}} \pm 7.04$ & $71.00^{\mathrm{ay}} \pm 3.44$ & 0.032 & & & \\
\hline & $P_{F}$ & 0.039 & 0.011 & NS & 0.021 & & & & \\
\hline \multirow[t]{3}{*}{ Head movement } & Floor-feed & $5.60 \pm 0.98$ & $6.40^{x} \pm 0.68$ & $5.60 \pm 2.93$ & $3.20 \pm 1.50$ & NS & NS & 0.042 & NS \\
\hline & Scatter-feed & $4.40 \pm 0.51$ & $3.60^{y} \pm 0.87$ & $2.60 \pm 0.87$ & $2.80 \pm 0.80$ & NS & & & \\
\hline & $P_{F}$ & NS & 0.012 & NS & NS & & & & \\
\hline \multirow[t]{3}{*}{ Preening } & Floor-feed & $0.40^{y} \pm 0.25$ & $0.20^{y} \pm 0.20$ & $0.60 \pm 0.60$ & $0.60 \pm 0.60$ & NS & 0.031 & NS & NS \\
\hline & Scatter-feed & $2.80^{a x} \pm 0.37$ & $1.40^{a b x} \pm 0.40$ & $0.60^{b} \pm 0.25$ & $2.40^{a} \pm 0.87$ & 0.033 & & & \\
\hline & $P_{F}$ & 0.009 & 0.037 & NS & NS & & & & \\
\hline \multirow[t]{3}{*}{ Foraging } & Floor-feed & $0.80 \pm 0.37$ & $0^{y}$ & $0.40 \pm 0.40$ & $0^{y}$ & NS & 0.028 & NS & NS \\
\hline & Scatter-feed & $4.20 \pm 2.33$ & $8.40^{x} \pm 1.21$ & $4.20 \pm 2.96$ & $5.00^{x} \pm 1.76$ & NS & & & \\
\hline & $P_{F}$ & NS & $<0.001$ & NS & $<0.001$ & & & & \\
\hline \multirow[t]{3}{*}{ Meaning-less pecking } & Floor-feed & $0.20^{y} \pm 0.20$ & $2.00 \pm 1.52$ & $2.00 \pm 0.71$ & $3.00 \pm 1.55$ & NS & 0.019 & NS & NS \\
\hline & Scatter-feed & $8.00^{a x} \pm 1.93$ & $1.00^{b} \pm 0.32$ & $4.20^{\mathrm{ab}} \pm 1.40$ & $1.60^{b} \pm 0.75$ & 0.036 & & & \\
\hline & $P_{F}$ & 0.033 & NS & NS & NS & & & & \\
\hline
\end{tabular}

$P_{L}$, the effect of transportation time on behavior during rest; $P_{F}$, the effect of feeding pattern on behavior during rest.

1) Results of one-factor analysis of variance.

${ }^{2)}$ Results of two-factor analysis of variance.

NS, No significant difference $(p>0.05)$.

${ }^{a, b}$ Significant difference in a row $(p<0.05)$.

${ }^{x, y}$ Significant difference in a column $(p<0.05)$. 
Table 5. Effect of the length of transport and the feed pattern on struggle behavior before slaughter of broilers at 54-days

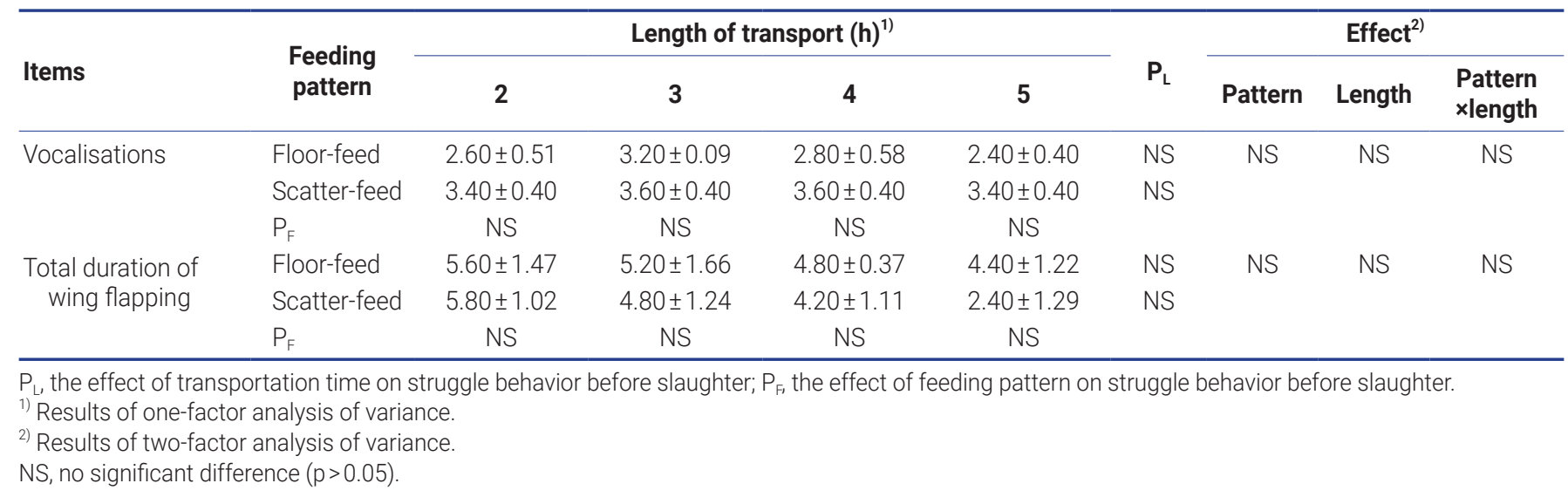

effect of transport time on the weight loss of poultry in our study, which is mainly due to the small number of broilers and better feeding conditions. At the same time, we carried out a unified long-term feeding treatment for broilers before transportation and reduced the weight effect caused by different excreta exclusion types in different feeding methods.

\section{Effects of different transport times on meat quality of broilers}

The appearance quality of poultry meat is a key factor which influences consumers' purchase desire and cooking experience. Transport stress can devalue ketone bodies resulting in changing flesh color and increasing drip loss [21]. Conspicuous changes in drip loss, $\mathrm{a}^{*}$ value and $\mathrm{L}^{*}$ value were found, suggesting that prolonged transport stress time reduced meat quality.

The main factors effecting the color of poultry meat are the content of myoglobin and the chemical state and reaction of myoglobin of meat which were closely impacted by the products of transport stress [22,23]. Metabolite products (such as reactive oxygen species, free radicals, lactic acid or phosphoric acid) can damage sensitive muscle cell membranes, resulting in myoglobin infiltration into the blood and an increase in $L^{*}[4,11,21]$. The content of myoglobin in breast muscle cells is low, and pale, soft and exudative (PSE) meat is easily stimulated by pre-mortem stress $[7,21]$. The $\mathrm{L}^{*}$ value was significantly increased with transportation time as noted in our experimental results $(\mathrm{p}<0.05)$, and the value in the $4 \mathrm{~h}$ group began to be higher than 50 , suggesting the risk of negative meat quality change as a $L^{*}$ value above 50 increases the risk of PSE meat [21]. The red value $\left(\mathrm{a}^{*}\right)$ of meat is usually influenced by pigment state and structure [21,23]. The fresh muscle colour favoured by consumers mainly comes from the red oxygenated myoglobin which can reversibly convert to the brown metmyoglobin and is affected by the changing temperature, $\mathrm{pH}$, oxidation degree of the transport pressure $[11,21,23]$. In this experiment, $\mathrm{a}^{*}$ value of scatter-feed broilers changed significantly with the extension of transportation time. In view of the insignificant changes in muscle $\mathrm{pH}$, we believe that it is mainly due to the cellular oxidative stress caused by the emotional stress. The level of fear was increased when scatter-feed broilers were moved from free rearing space to narrow cages. The product of cellular oxidative stress alters the state of hemoglobin, changing the red color of muscle [21]. Our experimental results were the same as Pan et al [6] and the pectoral muscle $\mathrm{a}^{*}$ decreased significantly at $3 \mathrm{~h}$. As the muscle of white meat, consumers are not sensitive to small amounts of light red. The influence of meat color on purchasing desire mainly depends on $L^{*}$ value.

The water loss of meat quality was affected by the hydrophilic ability of intracellular proteins and the integrity of the cell structure $[11,21]$. Transport stress cause drip loss because free radicals and acidic substances produced after transport will undermine the protein structure and decrease its hydrophilicity, damaging the cell membrane and making the exosmosis of cells contents [21-23]. High drip loss will affect the taste of raw meat when it is converted to cooked meat $[22,23]$. The mean values of different feeding groups and the two groups in the $4 \mathrm{~h}$ group were significantly increased, suggesting that the threshold of cell self-regulation may have been exceeded.

Contrary to the prediction, transport stress did not cause a significant change in $\mathrm{pH}_{1}$ which is affected by the level of glycolysis in cells. This is caused by the removal of acid substances during the recovery process, and the irreversible damage to the cell structure cannot be recovered immediately, so that meat quality does not change synchronously. Therefore short-distance transport stress increases mortality, while prolonged rest reduces meat injury $[1,22]$. Of course, it has been suggested that economic losses caused by ketone body depreciation can be reduced by extending the rest period before slaughter, but this seems inconsistent with the purpose of efficient intensive production [22]. 
The effect of feeding methods on $\mathrm{pH}$ value is different from that of Dal Bosco et al [24], the $\mathrm{pH}_{2}$ of scatter-feed broilers at $3 \mathrm{~h}$ was significantly lower than that of our different results. $\mathrm{pH}_{2}$ which negatively correlated with glycogen content was different from $\mathrm{pH}_{1}$ which mainly affected by the level of cell glycolysis $[21,24]$. On the one hand, our breeding space was not big enough for poultry to fly much, so as the glycogen content in muscles was not low before transportation. On the other hand, the activity resting behavior of floor-feed broilers during the recovery process was significantly higher than that of scatter-feed broilers $(\mathrm{p}<0.05)$, which increased the consumption of glycogen reserve. Finally, the level of $\mathrm{pH}_{2}$ of scatter-feed broilers in $3 \mathrm{~h}$ group was lower than that in floor-feed group.

\section{Effects of different transport times on behavior during rest of broilers}

Behavior is an important indicator of animal welfare. In a naturally stress-free environment, birds could show natural behavior, such as walking, exploring, foraging, fighting, decorating, and so on. When the poultry is in a state of stress, it produces behavioral disorders. Poultry behavior changed from excitement and anxiety to inhibition and depression with prolonged stress source stimulation time [18]. Dalton pointed that long-term transport pressure increased the attacking behavior of fire chickens [25]. Cashmana et al [18] also found that the tension static immobility time of chickens increased significantly, and then chickens were in fear stress. Our study showed that, the activity behavior decreased as longer transportation, suggesting that the anxiety of birds increased, which is consistent with Cheng and Jefferson [26]. But behavioral indicators in our study shown that, the stress response intensity was not simply negatively correlated with the length of transport time. Poultry behavior activity increased in the acute stress period to relieve the transport stress, while the chronic stress period decreased suggesting that poultry welfare has been compromised beyond broilers' self-regulating ability. As a whole, $3 \mathrm{~h}$ transport treatment seems to be the tipping point for behavioral change. In addition, as transport time increases, behaviour that could increase energy expenditure (standing and walking) are negatively correlated with behaviour that could decrease energy expenditure (lying), which can maintain stable cellular glycogen levels and change not significantly in $\mathrm{pH}_{2}$ [27].

Behavioral differences may also depend on different tissue function with floor-feed and scatter-feed. Due to the limited growth space and insufficient leg training, the bones of floorfeed group could not be effectively strengthened, and the mitochondrial activity of muscle cells was low [19]. Similar to our study, walking and standing behavior were least observed in floor-feed broilers in previous studies $[28,29]$.

\section{Effects of different transport times on struggling behavior before slaughter of broilers}

Poultry generally reacts to hanging by struggling, winging, screaming, or trying to raise their heads. Longer flapping time in hanging behavior can be regarded as an indication of escape behavior and discomfort [30]. The long flapping of wings indicates that poultry has a great sense of physical stress and psychological fear. Loud and long-term calls are natural responses of poultry to acute stress. Our results showed that the transport time had no significant effect on the flapping behavior and vocalization behavior of broilers before slaughter, which may be due to the panic and psychological stresses caused by the transport on poultry being relieved after resting for one hour at the end of the transport. Other acute stress factors concealed the effects of transport stress on poultry during the observation of the hanging experiment, and no significant differences were obtained. The experiment of M Debut was inconsistent with our findings and show that hanging influenced pre-mortem struggling behavior of poultry [31], which was due to the effect of hanging on pre-mortem struggling behavior of poultry without considering the factors of transport stress. And similarly, as Debut, our study showed that the $\mathrm{pH}_{2}$ of breast muscles changes synchronously with preslaughter struggle behavior. Again, the data suggests that glycogen level of breast muscle was changed by behavioral intensity after transport which would ultimately change $\mathrm{pH}_{2}$ level.

Transportation is inevitable in the process of poultry production. The transport time is affected by the distance from the farm to the slaughterhouse, the speed of the vehicle, choice of the route of transportation and weather conditions. As our experimental result reveals, the planning of comprehensive production and processing enterprises and the establishment of unified safety standards for transportation, transport time and feeding methods are important standards to be considered.

\section{CONCUSION}

In summary, the transport time threshold for broilers is 3 hours. Over 3 hours of transportation, broilers cannot alleviate the damage caused by transportation stress, resulting in lower $\mathrm{L}^{*}$ value of meat color and excessive drip loss. Scatterfeed broilers are more susceptible to panic than floor-feed broilers, which requires attention from the breeder during transportation to ensure the welfare of broilers.

\section{CONFLICT OF INTEREST}

We certify that there is no conflict of interest with any financial organization regarding the material discussed in the manuscript. 


\section{FUNDING}

This research was funded by the National Natural Science Foundation of China, grant number 32172785 .

\section{ACKNOWLEDGMENTS}

The authors thank the members of the animal behavior and welfare laboratory at the College of Animal Science and Technology in Northeast Agricultural University.

\section{REFERENCES}

1. Schwartzkopf-Genswein KS, Faucitano L, Dadgar S, Shand P, González LA, Crowe TG. Road transport of cattle, swine and poultry in North America and its impact on animal welfare, carcass and meat quality: a review. Meat Sci 2012; 92:227-43. https://doi.org/10.1016/j.meatsci.2012.04.010

2. Arikan MS, Akin AC, Akcay A, et al. Effects of transportation distance, slaughter age, and seasonal factors on total losses in broiler chickens. Braz J Poult Sci 2017;19:421-8. https:// doi.org/10.1590/1806-9061-2016-0429

3. Gou Z, Abouelezz KFM, Fan Q, et al. Physiological effects of transport duration on stress biomarkers and meat quality of medium-growing Yellow broiler chickens. Animal 2021; 15:100079. https://doi.org/10.1016/j.animal.2020.100079

4. Sowińska J, Wójcik A, Pomianowski J, et al. Effects of different variants of pre-slaughter transport on body weight loss and meat quality in broiler chickens. Med Weter 2013; 69:420-3.

5. Zhang C, Geng ZY, Chen KK, Zhao XH, Wang C. L-theanine attenuates transport stress-induced impairment of meat quality of broilers through improving muscle antioxidant status. Poult Sci 2019;98:4648-55. https://doi.org/10.3382/ ps/pez164

6. Pan L, Ma XK, Zhao PF, et al. Forsythia suspensa extract attenuates breast muscle oxidative injury induced by transport stress in broilers. Poult Sci 2018;97(Supp5):1554-63. https:// doi.org/10.3382/ps/pey012

7. Spurio RS, Soares AL, Carvalho RH, et al. Improving transport container design to reduce broiler chicken PSE (pale, soft, exudative) meat in Brazil. Anim Sci J 2016;87:277-83. https:// doi.org/10.1111/asj.12407

8. Dadgar ES, Lee E, Leer TLV, et al. Effect of microclimate temperature during transportation of broiler chickens on quality of the Pectoralis major muscle. Poult Sci 2010;89: 1033-41. https://doi.org/10.3382/ps.2009-00248

9. Owens CM, Sams AR. The influence of transportation on turkey meat quality. Poult Sci 2000;79:1204-7. https://doi. org/10.1093/ps/79.8.1204

10. Ali MS, Kang GH, Joo ST. A review: influences of pre-slaughter stress on poultry meat quality. Asian-Australas J Anim Sci
2008;21:912-6. https://doi.org/10.5713/ajas.2008.r.06

11.Archile-Contreras A, Purslow P. Oxidative stress may affect meat quality by interfering with collagen turnover by muscle fibroblasts. Food Res Int 2011;44:582-8. https://doi.org/10. 1016/j.foodres.2010.12.002

12. Font-i-Furnols M, Guerrero L. Consumer preference, behavior and perception about meat and meat products: an overview. Meat Sci 2014;98:361-71. https://doi.org/10.1016/j.meatsci. 2014.06.025

13. Gray JI, Gomaa EA, Buckley DJ. Oxidative quality and shelf life of meats. Meat Sci 1996;43:111-23. https://doi.org/10. 1016/0309-1740(96)00059-9

14.Jiang S, Jiang Z, Lin Y, Zhou G, Chen F, Zheng C. Effects of different rearing and feeding methods on meat quality and antioxidative properties in Chinese Yellow male broilers. $\mathrm{Br}$ Poult Sci 2011;52:352-8. https://doi.org/10.1080/00071668. 2011.569926

15. Sprafke H, Palme R, Schmidt P, Erhard M, Bergmann S. Effect of two transport options on the welfare of two genetic lines of organic free range pullets in Switzerland. Animal 2018;8: 183. https://doi.org/10.3390/ani8100183

16.World Organization for Animal Health [Internet]. In: Global conference on animal welfare: An OIE initiative 2004; 2004 Feb 23-5; Paris, France. Rome, Italy. Available from: https:// www.altex.org/index.php/altex/article/download/974/990

17.Speer NC, Slack G, Troyer E. Economic factors associated with livestock transportation. J Anim Sci 2001;79(suppl_E): E166-70. https://doi.org/10.2527/jas2001.79E-SupplE166x

18. Cashmana PJ, Nicol CJ, Jones RB. Effects of transportation on the tonic immobility fear reactions of broilers. Br Poult Sci 1989;30:211-21. https://doi.org/10.1080/0007166890 8417141

19. Dixon LM. Slow and steady wins the race: the behaviour and welfare of commercial faster growing broiler breeds compared to acommercial slower growing breed. PLoS ONE 2020;15:e0231006. https://doi.org/10.1371/journal. pone. 0231006

20. Aral Y, Arıkan MS, Akın AC, Kaya Kuyululu ÇY, Güloğlu SC, Sakarya E. Economic losses due to live weight shrinkage and mortality during the broiler transport. Ankara Üniv Vet Fak Derg 2014;61:205-210.

21.Rchardson RJ, Mead GC. Poultry meat science: poultry science symposium series 1st ed. CAB International 1999 except Chapter 11 Crown; 1999. Report No.: 25.

22.Zhang L, Yue HY, Zhang HJ, et al. Transport stress in broilers: I. Blood metabolism, glycolytic potential, and meat quality. Poult Sci 2009;88:2033-41. https://doi.org/10.3382/ps.200900128

23. Bianchi M, Petracci M, Cavani C. The influence of genotype, market live weight, transportation, and holding conditions prior to slaughter on broiler breast meat color. Poult Sci 2006; 85:123-8. https://doi.org/10.1093/ps/85.1.123 
24.Dal Bosco A, Mugnai C, Rosati A, Paoletti A, Caporali S, Castellini C. Effect of range enrichment on performance, behavior, and forage intake of free-range chickens. J Appl Poult Res 2014;23:137-45. https://doi.org/10.3382/japr.201300814

25. Dalton HA, Wood BJ, Torrey S. Injurious pecking in domestic turkeys: development, causes, and potential solutions. Worlds Poult Sci J 2013;69:865-76. https://doi.org/10.1080/194763 37.2016.1196246

26. Cheng HW, Jefferson L. Different behavioral and physiological responses in two genetic lines of laying hens after transportation. Poult Sci 2008;87:885-92. https://doi.org/10.3382/ ps.2007-00482

27. Warriss PD, Kestin SC, Brown SN, et al. The depletion of glycogen stores and indices of dehydration in transported broilers. Br Vet J 1993;149:391-8. https://doi.org/10.1016/ S0007-1935(05)80078-8

28.Zupan M, Berk J, Ellendorff F, et al. Resting behaviour of broilers in three different rearing systems. Poljopr Znan Smotra 2003;68:139-43.

29. Fouad MA, Abdel Razek AH, Badawy ESM. Broilers welfare and economics under two management alternatives on commercial scale. Int J Poult Sci 2008;7:1167-73.

30.Sparrey JM, Kettlewell PJ. Shackling of poultry: is a welfare problem? Worlds Poult Sci J 1994;50:167-76. https://doi.org/ 10.1079/WPS19940014

31. Debut M, Berri C, Arnould C, et al. Behavioural and physiological responses of three chicken breeds to pre-slaughter shackling and acute heat stress. Br Poult Sci 2005;46:527-35. https://doi.org/10.1080/00071660500303032 